\title{
Tribute to the Memory of Professor Gordon Kimber
}

I was deeply sorry to receive the sad news on my dear friend Gordon, whose friendship, discussions and exchange of scientific information I miss so much.

I remember with nostalgia Gordon's lab in Columbia Missouri, which was very active in scientific doing. Students from the USA and many foreign countries were instructed by him and enjoyed his great knowledge and clear presentations. Gordon was a superb lecturer and his presentations were always informative. His rich English vocabulary was well appreciated and known in the scientific community. I was lucky to spend several years in his lab. Needless to say, these years were full of creative experiences. Our collaborative studies were always fruitful. In addition, like other foreign scientists, working near him improved my ability to express myself in English. One of our fruitful teamwork endeavors was the writing of a book on the wild species that are closely related to domesticated wheat. This was an uncommon experience that I remember with great pleasure.

Gordons scientific studies concentrated on the cytogenetic and evolutionary relationships between the various species of wheat and related wild species. He focused mainly on the evolution of the polyploid species that include common (bread) wheat and durum (macaroni) wheat. The polyploid species contain two or three genomes of the diploid species. Gordon knew to efficiently use a variety of cytogenetic methods to elucidate the genomic structure of several polyploid species such as Triticum timopheevii and Aegilops recta, which are related to domesticated wheat. He also reassessed the course of evolution of bread wheat. Gordon developed and used a mathematical method that enabled him to obtain more accurate information on the cytogenetic relationships and on the genomic affinities between the diploid and the polyploid species of the group. This method advanced our understanding of the origin of the polyploid species and their course of development as well as their influence on wheat breeding.

In his applied studies, Gordon designed and developed methods and gathered plant material enabling the efficient utilization of the genes of wild relatives of wheat for improvement of domesticated wheat. He was among the pioneers in using a modern cytogenetic approach to identify the chromosomes of rye, a close relative to wheat. The chromosomes of rye are very similar morphologically and Gordon's identification of the various rye chromosomes via $\mathrm{C}$-banding enabled him to determine the genetic homology (similarities) between individual rye chromosomes and wheat chromosomes. This facilitated more efficient use of rye genes for common wheat improvement.

During my and my family's stay in Columbia and many years after, we developed warm relationships with Gordon and his family. We remember with nostalgia the interesting and pleasant time.

We share with Gordon's family the sadness of the great loss. Our thoughts are with them in this great sorrow.

\author{
Moshe FeLdMan \\ Professor \\ Weizmann Institute of Science
}

